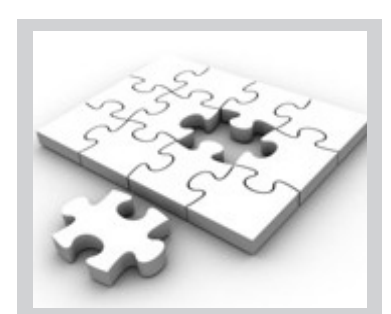

In an effort to facilitate the selection of appropriate peer reviewers for Journal of Transport and Supply

Chain Management, we ask that you take a moment to update your electronic portfolio on https:// jtscm.co.za for our files, allowing us better access to your areas of interest and expertise, in order to match reviewers with submitted manuscripts.

\section{If you would like to} become a reviewer, please visit the journal website and register as a reviewer.

To access your details on the website, you will need to follow these steps:

1. Log into the online journal at https://jtscm. co.za

2. In your 'user home' [https://jtscm.co.za/index. $\mathrm{php} / \mathrm{jtscm} /$ user] select 'edit my profile' under the heading 'my account' and insert all relevant details, bio statement and reviewing interest(s).

3. It is good practice as a reviewer to update your personal details regularly to ensure contact with you throughout your professional term as reviewer to the Journal of Transport and Supply Chain Management.

Please do not hesitate to contact us if you require assistance in performing this task.

\section{Publisher:}

publishing@aosis.co.za

Tel: +27 219752602

Tel: 0861000381

\title{
Acknowledgement to reviewers
}

The editorial team of the Journal Transport and Supply Chain Management recognises the value and importance of the peer reviewer in the overall publication process - not only in shaping the individual manuscript, but also in shaping the credibility and reputation of our journal.

We are committed to the timely publication of all original, innovative contributions submitted for publication. As such, the identification and selection of reviewers who have expertise and interest in the topics appropriate to each manuscript are essential elements in ensuring a timely, productive peer review process.

We would like to take this opportunity to thank all reviewers who participated in shaping this volume of the Journal of Transport and Supply Chain Management. We appreciate the time taken to perform your review(s) successfully.

\author{
Abel Dzuke \\ Akyene Tetteh \\ Albert T. Agbenyegah \\ Aletta S. Tolmay \\ Amanda Badenhorst \\ Andrea Appolloni \\ Andrew Jenkins \\ Andries Botha \\ Arvind Jayant \\ Benedict B. Ayantoyinbo \\ Chengedzai Mafini \\ Christopher J. Savage \\ Dave van der Meulen \\ David I. Pooe \\ Douglas N. Raza \\ Elmarie Kriel \\ Elvin Shava \\ Ernest Bhero \\ Fanny Saruchera \\ Feizel Ally \\ Francis I. Ojadi \\ Gerard de Villiers \\ Gerhardus van Zyl \\ Ghada I. Elkady
}

Hans W. Ittmann

Hubert Joynt

Hannie A. Badenhorst-Weiss

Jackie Walters

James R. Stock

Jan W. Proper

Jyoti D. Darbari

Marinda Pretorius

Marius Pretorius

Nurudeen A. Ajayi

Osman T. Aydas

Peter J. Kilbourn

Petrus J.V.V. Coetzee

Portia P.S. Sifolo

Progress Hove-Sibanda

Rose Luke

Smart Dumba

Stephen Carstens

Sumayah Goolam Nabee

Tatenda Mbara

Themari Eicker

Thobeka K.T. Ngcamphalala

Thuso Mphela 